\title{
c-Abl Contributes to Glucose-Promoted Apoptosis via p53 Signaling Pathway in Podocytes
}

Yiqiong Ma, Qian Yang, Xinghua Chen, Wei Liang, Zhilong Ren,

Guohua Ding*

Division of Nephrology, Renmin Hospital of Wuhan University, Wuhan,

China

*Corresponding author, Guohua Ding, MD, PhD.

Division of Nephrology

Renmin Hospital of Wuhan University

238 Jiefang Road, Wuhan, Hubei 430060 (China)

Fax: +862788042292

E-Mail: ghxding@gmail.com 


\section{ABSTRACT}

Aim: To investigate the role of the non-receptor tyrosine kinase c-Abl in high glucose-induced podocyte injury and its possible signal transduction pathway.

Methods: Sixteen C57BL/6 mice were randomly assigned to a group with diabetes and a normal control group. Subsequently, differentiated mouse podocytes were exposed to high-glucose conditions, and podocyte apoptosis was then assessed by flow cytometry and Hoechst 33258 staining. Western blot and immunofluorescence assay were used to measure c-Abl expression. Co-immunoprecipitation assay was used and c-Abl siRNA was applied to evaluate the interaction between c-Abl and p53.

Results: High glucose promotes podocyte apoptosis. The c-Abl expression in podocytes was increased after exposure to high glucose, stimulating the p53 signaling pathway. Conversely, treatment with c-Abl siRNA restored high glucose-promoted podocyte apoptosis and resulted in the reduction of $\mathrm{p} 53$ expression.

Conclusion: c-Abl contributes to high glucose-induced podocyte apoptosis via p53 signaling pathway. 
Key words:

Podocytes; High glucose; c-Abl; Apoptosis 


\section{Introduction}

Podocytes are terminally differentiated cells that contribute to maintaining the integrity of the glomerular basement membrane [1]. Recent studies have shown that podocyte injury is involved in several glomerular diseases [2-5]. Diabetic nephropathy (DN) is considered the leading cause of end-stage renal disease in Western countries, and podocytes have been confirmed to play a vital role in the development of the pathological changes that characterize $\mathrm{DN}$, including podocytopenia, hypertrophy, glomerulosclerosis, and apoptosis [6].

c-Abl, which belongs to the Abl family, contains SH2 and SH3 structural domains of tyrosine kinase for specific binding. A $140 \mathrm{kDa}$ protein, c-Abl is considered as a Src-related non-receptor tyrosine kinase conserved during evolution but ubiquitously expressed in many tissues, including kidney [7-9]. In recent studies, c-Abl is confirmed to have multiple biological functions. It also has a correlation with aggressive tumors [10] and plays an important role in inflammatory diseases [11]. In addition, many studies point toward the role of c-Abl in the signal transduction pathways that are invovled in apoptotic signaling and cytoskeletal rearrangement [12-15]. As a tumor suppressor, p53 plays a key role in many biological processes. The best-understood function of p53 is supporting cell survival and promoting cell death [16, 17]. Accumulating 
evidence demonstrates that $\mathrm{p} 53$ signaling contributes to the progession of several kidney diseases [18]. It is also implicated in the pathogenesis of DN [19]; p53 expression is increased and activated in the glomeruli of mice whit type 1 and type 2 diabetes mellitus [20,21]. Our previous study indicated that c-Abl up-regulation promotes podocyte apoptosis upon exposure to angiotensin II [22]. However, the function of c-Abl in high glucose-induced podocyte injury remains to be clarified. The present study further investigates the role of c-Abl in podocyte injury under high-glucose conditions. 


\section{Subjects}

In this study, mice with diabetes were used to investigate the effects of hyperglycemia on the c-Abl expression in glomeruli. Furthermore, conditionally immortalized murine podocytes were cultured in a high-glucose environment to elucidate the role of c-Abl in podocyte apoptosis and the underlying signaling pathway. 


\section{Materials and Methods}

\subsection{Animals}

The experimental procedures and protocols were approved by the Ethical Committee for the Experimental Use of Animals of Renmin Hospital of Wuhan University in Wuhan, China. Sixteen male C57BL/6 mice were supplied by the Research Center of Medical Experimental Animals of Wuhan University. A combination of high-fat diet (HFD) and low-dose streptozotocin (STZ) was used to induce type 2 diabetes in mouse model $[23,24]$. The method was performed as described previously [25]. Briefly, the mice were randomly assigned to the group with diabetes on a purified high-fat diet consisting of $24 \%$ total fat, $24 \%$ protein, and $48 \%$ carbohydrate (45\% calories from fat; D12541, Research Diets) and the control group on a normal chow diet. The animals were housed under a $12 \mathrm{~h}$ light-dark cycle and a temperature of $22{ }^{\circ} \mathrm{C}$. Eight-week-old experimental mice were each intraperitoneally injected with a single dose of STZ (50 mg/kg). Age-matched control mice received an equal volume of $0.1 \mathrm{M}$ citrate buffer $(\mathrm{pH} 4.5)$. Blood glucose in the blood from tail vein was measured. Mice with blood glucose levels over $16 \mathrm{mmol} / \mathrm{L}$ were considered as having diabetes. At 12 weeks post-STZ injection, mice were individually placed into metabolic cages for $24 \mathrm{~h}$ and urine was collected for subsequent analysis. Urinary albumin concentration was 
measured using a mouse albumin ELISA quantification kit (Bethyl Laboratories, USA).Then the mice were sacrificed and the kidneys were harvested. The cortices of the kidneys were isolated and fixed in $4 \%$ phosphate-buffered paraformaldehyde for renal pathological analysis.

\subsection{Cell culture and treatment}

Conditionally immortalized murine podocytes were kindly provided by Dr. Peter Mundel (Mount Sinai School of Medicine, New York, USA). The cells were grown at $33{ }^{\circ} \mathrm{C}$ in RPMI 1640 medium (HyClone, USA) containing 10\% heat-inactivated fetal calf serum (Gibco, USA), $100 \mathrm{U} /$ $\mathrm{mL}$ penicillin $\mathrm{G}, 100 \mu \mathrm{g} / \mathrm{mL}$ streptomycin, and $10 \mathrm{U} / \mathrm{mL}$ recombinant murine interferon- $\gamma$ (IFN- $\gamma$, Sigma-Aldrich, USA) in the presence of 5\% $\mathrm{CO}_{2}$. Proliferating cells were transferred to an incubator at $37^{\circ} \mathrm{C}$ in IFN- $\gamma$-free medium for 7-14 days to induce differentiation. Differentiated podocytes were cultured for $24 \mathrm{~h}$ in a medium containing $5 \mathrm{mM}$ glucose (normal glucose) for control group, $5 \mathrm{mM}$ glucose $+25 \mathrm{mM}$ mannitol for the hypertonic control group, and $30 \mathrm{mM}$ glucose (high glucose) for the experimental group.

\section{3. $c$-Abl siRNA transfection}

Before transfection, $2 \times 10^{5}$ cells per well were seeded in 6-well plates. Subsequently, $10 \mathrm{nmol} / \mathrm{L}$ c-Abl siRNA (QIAGEN, Germany) was 
applied to each well. The siRNA transfection was carried out using HiPerfect Transfection Reagent (QIAGEN, Germany) according to the manufacturer's instructions. Transfected Cells were incubated at $37^{\circ} \mathrm{C}$ for $72 \mathrm{~h}$

\subsection{Western blot}

The cells were rinsed with ice-cold phosphate-buffered saline (PBS) and lysed in RIPA buffer (150 mM sodium chloride; $1.0 \%$ Triton X-100; 0.5\% sodium deoxycholate; $0.1 \%$ sodium dodecyl sulfate; $50 \mathrm{mM}$ Tris, $\mathrm{pH} 8.0$ ) mixed with protease inhibitors (P8340, Sigma-Aldrich) for $30 \mathrm{~min}$ on ice. Samples were collected and centrifuged at $12,000 \mathrm{rpm}$ for $10 \mathrm{~min}$ at $4{ }^{\circ} \mathrm{C}$. Supernatant protein was boiled in loading buffer at $100{ }^{\circ} \mathrm{C}$ for $5 \mathrm{~min}$. The protein samples were subjected to SDS-PAGE and transferred to nitrocellulose membranes (GE Healthcare, USA). After blocking with milk, membranes were incubated with primary antibodies (c-Abl rabbit polyclonal antibody, 1:200, Santa Cruz Biotechnology, USA; p53 mouse polyclonal antibody, 1:100, Santa Cruz Biotechnology; $\beta$-actin mouse monoclonal antibody, control, 1:1,000, Santa Cruz Biotechnology) overnight at $4{ }^{\circ} \mathrm{C}$. IRDye $800 \mathrm{CW}$ conjugated purified goat anti-mouse IgG (1:5,000, LI-COR Biosciences,USA) was used as a secondary antibody. The bands were visualized with an Odyssey infrared imaging system (LI-COR Biosciences). 


\subsection{Co-immunoprecipitation}

Protein lysates were mixed with p53 mouse polyclonal antibody (Santa Cruz Biotechnology) and incubated at $4{ }^{\circ} \mathrm{C}$ over night. Then, the supernatants loaded with protein $\mathrm{A}+\mathrm{G}$ agarose were applied for $3 \mathrm{~h}$ at

$4{ }^{\circ} \mathrm{C}$. After the centrifuged sediments were collected, bound proteins were eluted by boiling in loading buffer at $95{ }^{\circ} \mathrm{C}-100{ }^{\circ} \mathrm{C}$ for $5 \mathrm{~min}$. Then, the protein samples were analyzed by Western blot for c-Abl and p53.

\subsection{Apopotosis assays}

Hoechst 33258 (Sigma-Aldrich) staining was employed to assess podocyte apoptosis in vitro. The prepared cells were fixed in $4 \%$ paraformaldehyde at room temperature for $10 \mathrm{~min}$, and then stained with Hoechst 33258 for $5 \mathrm{~min}$ at room temperature. Subsequently, cells were rinsed thrice with ice-cold PBS. Podocytes were observed under a fluorescence microscope (DP72, Olympus, Japan), and all microscopic images were recorded.

Flow cytometry was also performed to evaluate podocyte apoptosis in vitro. Fluorescein isothiocyanate (FITC)-conjugated annexin V and PI (KGA108, KeyGen Biotech, China) were used to identify apoptotic cells according to the manufacturer's instructions. Cells in the upper-right and 
lower-right quadrants were classified as apoptotic.

\subsection{Immunofluorescence assay}

The cell-climbing films were fixed with $4 \%$ paraformaldehyde for $30 \mathrm{~min}$ at $4{ }^{\circ} \mathrm{C}$ and stained with c-Abl antibody $(1: 100$, Santa Cruz

Biotechnology) overnight at $4{ }^{\circ} \mathrm{C}$. The films were then subjected to FITC-conjugated IgG at $37{ }^{\circ} \mathrm{C}$ for $45 \mathrm{~min}$. All microscopic images were recorded using a 12.8- megapixel camera (DP72, Olympus, Japan).

\subsection{Immunohistochemistry}

The c-Abl expression in the kidney tissue was visualized by immunostaining. The paraffin-embedded sections ( $3 \mu \mathrm{m}$ thick) were deparaffinized, treated with $3 \% \mathrm{H}_{2} \mathrm{O}_{2}$ for $30 \mathrm{~min}$ at room temperature, and then autoclaved in citrate buffer $(0.01 \mathrm{~mol} / \mathrm{L}, \mathrm{pH}$ 6.0) for $10 \mathrm{~min}$ for antigen retrieval. After blocking with $5 \%$ bovine serum albumin, the sections were incubated with c-Abl primary antibody (1:100, Abbiotec, USA) overnight at $4{ }^{\circ} \mathrm{C}$. Subsequently, they were incubated with biotin-conjugated secondary antibody and avidin-biotin peroxidase complex (Dako, USA) for 30 min. After DAB (Dako) staining, sections were stained with haematoxylin. The data were analyzed using Image-Pro Plus 5.10 software (Media Cybernetics, USA). 


\subsection{Statistical analyses}

All values were presented as mean \pm SD and analyzed with SPSS 17.0.

Differences in mean values were tested using student's t test or one-way ANOVA test. Differences are statistically if $p<0.05$. 


\section{Results}

\subsection{Effect of hyperglycemia on podocyte structure}

Table 1 demonstrates that the blood glucose levels and urinary albumin exercetion of the mice on a HFD were elevated. The kidneys of the mice with diabetes and those of the control mice were obtained to study the ultrastructure of glomeruli by electron microscopy. Representative electron microphotographs of podocytes in the two groups are shown in Fig. 1A. Podocytes foot processes (FPs) widening and effacement were evident in the group with diabetes. The cumulative data shown in Fig. 1B indicated that the mean FP (foot process) width of the group with diabetes significantly increased.

\subsection{Effect of hyperglycemia on c-Abl expression in vivo}

Our previous study demonstrated the expression of c-Abl in glomeruli. To test the pattern of the expression of c-Abl under hyperglycemic conditions, we established the mouse model of diabetes. The renal cortical sections of the mice were assessed by immunohistochemistry staining, and a significant increase of c-Abl expression was found in the 
glomeruli of mice with diabetes (Figs. 2A and B). Western blot was employed to analyze c-Abl expression quantitatively and consequently confirm such an increase, and the increased c-Abl expression was detected in the glomeruli of the mice with diabetes (Fig. 2C).

\subsection{Effect of high glucose on c-Abl expression and distribution in cultured podocytes}

The increased expression of c-Abl was also detected in podocytes exposed to high glucose in vitro. As shown in Fig. 3A, the level of c-Abl expression dramatically increased after $24 \mathrm{~h}$ in high-glucose $(30 \mathrm{mM})$ medium, and the increased expression of c-Abl was also detected in cells exposed to tapered concentrations of glucose (Fig. 3B). In addition, the immunofluorescence assays indicated that the amount of c-Abl fluorescence in the nucleus dramatically increased in high glucose-treated cells. The results suggested that the high glucose-promoted expression and distribution of c-Abl might be involved in the biological changes in podocytes in diabetes.

\subsection{Effect of c-Abl on high glucose-induced apoptosis}

To evaluate the role of c-Abl in high glucose-induced podocyte apoptosis, we used c-Abl siRNA to suppress the expression of c-Abl (Fig. 4). The results (Figs. 4A and B) indicated that c-Abl-specific siRNA reduced the 
c-Abl expression in cultured podocytes treated with high glucose. In addition, the amount of c-Abl fluorescence in the nucleus was also reduced (Fig. 4A). Hoechst 33258 staining and flow cytometry were used to assess podocyte apoptosis (Fig. 4C and D). As shown in Figs. 3C and D, high-glucose exposure significantly enhanced podocyte apoptosis. Reversely, the down-regulation of c-Abl with siRNA prevented podocyte apoptosis caused by high glucose. These findings indicated that c-Abl was involved in the signaling pathways in podocyte injury promoted by high glucose.

\subsection{Effect of high glucose on c-Abl-p53 interaction}

A well-known tumor suppressor, p53 is also involved in the process of apoptosis. Podocytes were treated with a high concentration $(30 \mathrm{mM})$ of glucose for $24 \mathrm{~h}$. PBS- and mannitol-treated groups were used as the normal and hypertonic control groups, respectively. The expression of p53 protein was markedly up-regulated in high glucose-treated cells (Fig. 4B). Conversely, the knock-down of c-Abl by specific siRNA diminished the high-glucose-induced up-regulation of p53 (Fig. 4B). This result indicated that the expression of p53 was up-regulated, and c-Abl was essential for this up-regulation under high-glucose conditions. Furthermore, we tested the interaction between endogenous c-Abl and p53 in podocytes with the use of co-immunoprecipitation. c-Abl was able 
to interact with p53 under normal conditions (Fig. 5). High-glucose treatment promoted the interaction of c-Abl with $\mathrm{p} 53$, which was diminished by c-Abl siRNA (Fig. 5).

\section{Discussion}

This study reveals the important role of c-Abl in the process of podocyte apoptosis, which is a common pathological phenomenon in a range of glomerular diseases, including DN. The typical clinical presentation of $\mathrm{DN}$ is the onset of urinary albumin excretion and the progression of renal dysfunction, which is pivotally attributed to podocyte dysfunction. Our previous study demonstrated the expression of c-Abl in podocytes and indicated that c-Abl up-regulation promoted podocyte apoptosis upon exposure to angiotensin II [22].

As a non-receptor tyrosine kinase, c-Abl contains several domains that are essential for target protein binding. The core of c-Abl is composed of tandem SH3 and SH2 domains, which bind to a substrate. The C-terminal region of c-Abl contains an actin-binding domain, which specifies the location of F-actin, and nuclear localization signals, which drive the nuclear entry of c-Abl. Furthermore, several PxxP motifs for SH3 domains interactions and DNA-binding motifs provide additional location cues $[7,26]$. Several cellular behaviors are believed to be triggered by c-Abl, including actin rearrangement, immune response, and apoptosis 
[26-28]. Recent studies $[29,30]$ have put forward the vital role of c-Abl in the pathogenesis of nerve diseases. Neural cells and podocytes are highly dynamic cells with dendritic spines or foot processes and share similar structures and functions. However, the role of c-Abl in the biology functions of podocytes remains elusive. Our results indicated that high-glucose treatment increased the expression of c-Abl in glomeruli and cultured podocytes and that the knockdown of c-Abl prevented the high glucose-induced apoptosis of podocytes. A previous study [11] reported that c-Abl plays an important role in prion-induced neuronal apoptosis. In addition, Chung et al. [31] indicated that up-regulation of c-Abl contributes to the $\mathrm{Kr} 28$-induced apoptosis of PC-3 human prostate carcinoma cells. Collectively, these results suggest that the up-regulation of c-Abl is a pro-apoptosis signaling in response to high-glucose conditions.

Our study further confirms that p53 is involved in the process of podocyte apoptosis. Notably, after high glucose treatment, c-Abl clusters in the nucleus and interacts with p53. More interestingly, previous studies reported that the $\mathrm{C}$-terminus of $\mathrm{c}-\mathrm{Abl}$ contains a p53-binding domain [7] and that c-Abl-induced apoptosis is partially executed in a p53-dependent manner $[32,33]$. As a major tumor suppressor, p53 also plays a vital role in the progression of kidney diseases [34,35]. It has been reported to 
mediate high glucose-induced podocyte apoptosis [36]. As a nuclear transcription factor, p53 has the ability to mediate the expression of a large number of genes such as p21, Bax, p53INP1, Bid, and Puma [17, 37, 38]. Furthermore, p53 can be activated by a number of cellular stressors, including DNA damage, hypoxia, and oncogene activation [39]. Our results show that high glucose increases the expression of p53 in cultured podocytes, which display a considerable number of apoptotic cells. Moreover, the co-immunoprecipitation results confirm that high glucose stimulation promotes $\mathrm{p} 53-\mathrm{c}-\mathrm{Abl}$ interaction, which was abolished by the transfection with c-Abl siRNA. Thus, consistent with the results of previous studies, our results demonstrate that the c-Abl-p53 pathway contributes to high glucose-induced podocytes apoptosis $[32,33]$. However, the specific binding domains and other signaling pathways that contribute to c-Abl-associated podocytes apoptosis need to be further investigated. Mokhtari et al. [8] reported that imatinib mesylate, a 2-phenylaminopyrimidine-based ATP-competitive inhibitor of the Abl tyrosine kinase family, could stimulate ERK and Akt phosphorylation in a c-Abl-dependent manner. In addition, our previous study demonstrated that the ERK and Akt pathway play vital roles in the progression of kidney diseases [40, 41]. Thus, c-Abl possibly regulates ERK and Akt phosphorylation during the progression of $\mathrm{DN}$, and further research need to be undertaken to confirm this premise. 
In summary, the present study shows that high glucose directly promotes podocyte apoptosis and up-regulates c-Abl in podocytes in vivo and in vitro. c-Abl contributes to high glucose-induced podocyte apoptosis via the transcription factor $\mathrm{p} 53$. Thus, the c-Abl-p53 signaling pathway may be a new candidate for therapeutic targets to prevent podocyte injury during the progression of $\mathrm{DN}$. 


\section{Acknowledgements}

This study was supported by the grants from the National Science

Foundation of China (81270762 to G.D. and 81470912 to W.L.) and the

Natural Science Foundation of Hubei Province of China (2015CFB347 to

X.C.). 


\section{References}

[1]. Shankland SJ. The podocyte's response to injury: Role in proteinuria and glomerulosclerosis. Kidney International 2006; 69: 2131-2147.

[2]. Nangaku M, Shankland SJ, Couser WG. Cellular Response to Injury in Membranous Nephropathy. Journal of the American Society of Nephrology 2005; 16: 1195-1204.

[3]. Mundel P, Reiser J. Proteinuria: an enzymatic disease of the podocyte? Kidney International 2009; 77: 571-580.

[4]. Zhang C, Hu JJ, Xia M, Boini KM, Brimson C, Li PL. Redox signaling via lipid raft clustering in homocysteine-induced injury of podocytes. Biochimica et Biophysica Acta (BBA) - Molecular Cell Research 2010; 1803: 482-491. [5]. Campbell KN, Raij L, Mundel P. Role of angiotensin II in the development of nephropathy and podocytopathy of diabetes. Curr Diabetes Rev 2011; 7: 3-7. [6]. Wolf G, Chen S, Ziyadeh FN. From the periphery of the glomerular capillary wall toward the center of disease: podocyte injury comes of age in diabetic nephropathy. Diabetes 2005; 54: 1626-34.

[7]. Colicelli J. ABL Tyrosine Kinases: Evolution of Function, Regulation, and Specificity. Science Signaling 2010; 3: re6. doi: 10.1126/scisignal.3139re6.

[8]. Mokhtari D, Al-Amin A, Turpaev K, Li T, Idevall-Hagren O, Li J, et al. Imatinib mesilate-induced phosphatidylinositol 3-kinase signalling and improved survival in insulin-producing cells: role of Src homology 2-containing inositol 5' -phosphatase interaction with c-Abl. Diabetologia 2013; 56: 1327-1338.

[9]. Liu W, Wu J, Xiao L, Bai Y, Qu A, Zheng Z, et al. Regulation of Neuronal Cell Death by c-Abl-Hippo/MST2 Signaling Pathway. PLoS One 2012; 7: e36562. 
[10]. Koos B, Jeibmann A, Lünenbürger H, Mertsch S, Nupponen NN, Roselli A, et al. The tyrosine kinase c-Abl promotes proliferation and is expressed in atypical teratoid and malignant rhabdoid tumors. Cancer 2010; 116: 5075-5081.

[11]. Jackson RC, Radivoyevitch T. Modelling c-Abl Signalling in Activated Neutrophils: the Anti-inflammatory Effect of Seliciclib. Biodiscovery 2013; 7: 4. [12]. Estrada LD, Zanlungo SM, Alvarez AR. c-Abl tyrosine kinase signaling: a new player in AD tau pathology. Curr Alzheimer Res 2011; 8: 643-51.

[13]. Fred RG, Boddeti SK, Lundberg M, Welsh N. Imatinib mesylate stimulates low-density lipoprotein receptor-related protein 1-mediated ERK phosphorylation in insulin-producing cells. Clinical Science 2015; 128: 17-28.

[14]. Cleary RA, Wang R, Waqar O, Singer HA, Tang DD. Role of c-Abl tyrosine kinase in smooth muscle cell migration. Am J Physiol Cell Physiol 2014; 306: C753-61.

[15]. Karuppagounder SS, Brahmachari S, Lee Y, Dawson VL, Dawson TM, Ko HS. The c-Abl inhibitor, Nilotinib, protects dopaminergic neurons in a preclinical animal model of Parkinson's disease. Scientific Reports 2014; 4: 4874.

[16]. Jacson JG, Post SM, Lozano G. Regulation of tissue- and stimulus- specific cell fate decisions by p53 in vivo. Journal of Pathology 2011; 223: 127-136.

[17]. Megyeri K, Orosz L, Kemeny L. Vesicular stomatitis virus infection triggers apoptosis associated with decreased $\Delta \mathrm{Np63} a$ and increased Bax levels in the immortalized HaCaT keratinocyte cell line. Biomedicine \& Phamacotherapy 2007; 61: $254-260$.

[18]. Skirnisdottir I, Seidal T. The apoptosis regulators p53, bax and PUMA: Relationship and impact on outcome in early stage (FIGO I-II) ovarian carcinoma after post-surgical taxane-based treatment. Oncology Reports 2012; 27: 741-747 [19]. Chen YW, Chenier I, Chang SY, Tran S, Ingelfinger JR, Zhang SL. High glucose promotes nascent nephron apoptosis via NF- K B and p53 pathways. Am J Physiol Renal Physiol 2011; 300: F147-F156.

[20]. Carvajal LA, Manfredi JJ. Another fork in the road-life or death decisions by the tumour suppressor p53. European Molecular Biology Organization 2013; 14: 
414-421.

[21]. Deshpande SD, Putta S, Wang M, Lai JY, Bitzer M, Nelson RG, et al.

Transforming Growth Factor- $\beta$-Induced Cross Talk Between p53 and a MicroRNA in the Pathogenesis of Diabetic Nephropathy. Diabetes 2013; 62: 3151-3162. [22]. Chen X, Ren Z, Liang W, Zha D, Liu Y, Chen C, et al. c-Abl mediates angiotensin II-induced apoptosis in podocytes. Journal of Molecular Histology 2013; 44: 597-608.

[23]. Mu J, Woods J, Zhou YP, Roy RS, Li ZH, Zycband E, et al. Chronic Inhibition of Dipeptidyl Peptidase-4 With a Sitagliptin Analog Preserves Pancreatic $\beta$-Cell Mass and Function in a Rodent Model of Type 2 Diabetes. Diabetes 2006; 55 : 1695-1704.

[24]. Liu TY, Shi CX, Gao R, Sun HJ, Xiong XQ, Ding L, et al. Irisin inhibits hepatic gluconeogenesis and increases glycogen synthesis via PI3K/Akt pathway in type 2 diabetic mice and hepatocytes. Clin Sci 2015;129: 839-50

[25]. Shao ML, Lu XM, Cong WT, Xing X, Tan Y, Li YQ, et al. Multiple Low-Dose Radiation Prevents Type 2 Diabetes-Induced Renal Damage through Attenuation of Dyslipidemia and Insulin Resistance and Subsequent Renal Inflammation and Oxidative Stress. Plos One 2014; 9: e92574

[26]. Tegtmeyer N, Backert S. Role of Abl and Src family kinases in actin-cytoskeletal rearrangements induced by the Helicobacter pylori CagA protein. European Journal of Cell Biology 2011; 90: 880-890.

[27]. Dudek SM, Chiang ET, Camp SM, Guo Y, Zhao J, Brown ME, et al., Abl Tyrosine Kinase Phosphorylates Nonmuscle Myosin Light Chain Kinase to Regulate Endothelial Barrier Function. Mol Biol Cell 2010; 21: 4042-56.

[28]. Iqbal S, Zhang S, Driss A, Liu ZR, Kim HR, Wang Y, et al. PDGF Upregulates Mcl-1 Through Activation of $\beta$-Catenin and HIF-1 $\alpha$-Dependent Signaling in Human Prostate Cancer Cells. PLoS ONE 2012; 7: e30764.

[29]. Jia DY, Du ZH, Liu SM, Liu HJ, Wang FW, Ling EA, et al. c-Abl is involved in high glucose-induced apoptosis in embryonic E12.5 cortical neural progenitor cells from the mouse brain. Journal of Neurochemistry 2008; 106: 1720-30. 
[30]. Pan B, Yang L, Wang J, Wang Y, Wang J, Zhou X, et al. c-Abl tyrosine kinase mediates neurotoxic prion peptide-induced neuronal apoptosis via regulating mitochondrial homeostasis. Molecular Neurobiology 2014; 49: 1102-1116.

[31]. Chung KS, Han G, Kim BK, Kim HM, Yang JS, Ahn J, et al. A novel antitumor piperazine alkyl compound causes apoptosis by inducing RhoB expression via ROS-mediated c-Abl/p38 MAPK signaling. Cancer Chemotherapy and Pharmacology 2013; 72: 1315-1324.

[32]. Wang X, Zeng L, Wang J, Chau JF, Lai KP, Jia D, et al. A positive role for $\mathrm{c}-\mathrm{Abl}$ in Atm and Atr activation in DNA damage response. Cell Death and Differentiation 2010; 18: 5-15.

[33]. Furlan A, Stagni V, Hussain A, Richelme S, Conti F, Prodosmo A, et al. Abl interconnects oncogenic Met and p53 core pathways in cancer cells. Cell Death and Differentiation 2011; 18: 1608-1616.

[34]. Vashistha H, Meggs L. Diabetic nephropathy: lessons from the mouse. The Ochsner journal 2013; 13: 140-146.

[35]. Zhou LL, Cao W, Xie C, Tian J, Zhou Z, Zhou Q, et al., The receptor of advanced glycation end products plays a central role in advanced oxidation protein products-induced podocyte apoptosis. Kidney International 2012; 82: 759-770. [36]. Gao F, Yao M, Shi Y, Hao J, Ren Y, Liu Q, et al. Notch pathway is involved in high glucose-induced apoptosis in podocytes via Bcl-2 and p53 pathways. Journal of Cellular Biochemistry 2013; 114: 1029-1038.

[37]. Zhou Y, Zhang E, Berggreen C, Jing X, Osmark P, Lang S, et al. Survival of pancreatic beta cells is partly controlled by a TCF7L2-p53-p53INP1-dependent pathway. Hum Mol Genet 2012; 21: 196-207.

[38]. Skírnisdóttir I, Seidal T. The apoptosis regulators p53, bax and PUMA:

Relationship and impact on outcome in early stage (FIGO I-II) ovarian carcinoma after post-surgical taxane-based treatment. Oncol Rep 2012; 27:741-7.

[39]. Freed-Pastor WA, Prives C. Mutant p53: one name, many proteins. Genes Development 2012; 26: 1268-1286.

[40]. Chen C, Liang W, Jia J, van Goor H, Singhal PC, Ding G. Aldosterone Induces 
Apoptosis in Rat Podocytes: Role of PI3-K/Akt and p38MAPK Signaling Pathways. Nephron Experimental Nephrology 2009; 113: e26-34.

[41]. Liu Y, Liang W, Yang Q, Ren Z, Chen X, Zha D, et al. IQGAP1 Mediates Angiotensin II-Induced Apoptosis of Podocytes via the ERK1/2 MAPK Signaling Pathway. American Journal of Nephrology 2013; 38: 430-444 
Figure 1:

Effect of hyperglycemia on podocyte structure. A: Representative transmission electron microscopy images of glomerular capillary loops in two groups. Original magnification $\times 2000$, scale, $1100 \mathrm{~nm} . \quad B$ : Quantitative analysis of the FP (foot process) width ( $n=8, n$ represents the number of mice in each group). $* \mathrm{P}<0.05$ relative to control.

Figure 2:

Effect of hyperglycemia on c-Abl expression in vivo. A: Light microscopy evaluation of glomeruli c-Abl expression with immunohistochemistry staining in different groups. Original magnification $\times 400$, scale, $30 \mu \mathrm{m}$. (a1-a3, b1-b3): Representative microscopy images of glomeruli in normal and diabetes mice respectively. B: Quantitative analysis of glomeruli c-Abl expression integrated optical density ( $n=8, n$ represents the number of mice in each group). C: Western blot analysis of glomeruli c-Abl in different groups and quantitative analysis $\left(\mathrm{n}=8, \mathrm{n}\right.$ represents the number of mice in each group). ${ }^{*} \mathrm{P}<0.05$ relative to control.

Figure 3:

Expression and distribution of c-Abl in the cultured podocytes under the high-glucose treatment. A and B: Representative immunofluorescence results of c-Abl distribution in cultured podocytes with medium 
containing $30 \mathrm{mM}$ glucose at various time points and representative western blot and quantitation of these results $(n=3, n$ represents the number of repeat times). Original magnification $\times 400$, scale, $20 \mu \mathrm{m} . \mathrm{C}$ and D: Representative immunofluorescence results of c-Abl distribution in cultured podocytes exposed to different concentrations of glucose for $24 \mathrm{~h}$ and representative western blotting and quantitation of these results $(\mathrm{n}=3, \mathrm{n}$ represents the number of repeat times). Original magnification $\times$ 400, scale, $20 \mu \mathrm{m}$. $* \mathrm{P}<0.05$ compared with cells for $0 \mathrm{~h}$. ${ }^{\#} \mathrm{P}<0.05$ compared with cells exposed to normal glucose.

Figure 4:

Effect of high glucose on podocytes apoptosis. A. Representative immunofluorescence results of c-Abl distribution in cultured podocytes with different medium. Original magnification $\times 400$, scale, $20 \mu \mathrm{m}$. (a): 5 $\mathrm{mM}$ glucose for $24 \mathrm{~h}$. (b): $5 \mathrm{mM}$ glucose $+25 \mathrm{mM}$ mannitol for $24 \mathrm{~h}$. (c): $30 \mathrm{mM}$ glucose for $24 \mathrm{~h}$. (d): $30 \mathrm{mM}$ glucose + c-Abl siRNA for $24 \mathrm{~h}$. B. Western blot detection of c-Abl and p53 expression in cultured podocytes with different medium and quantitation of these results $(n=3, n$ represents the number of repeat times). (NG): $5 \mathrm{mM}$ glucose for $24 \mathrm{~h}$. (MA): $5 \mathrm{mM}$ glucose $+25 \mathrm{mM}$ mannitol for $24 \mathrm{~h}$. (HG): $30 \mathrm{mM}$ glucose for $24 \mathrm{~h}$. (HG + siRNA): $30 \mathrm{mM}$ glucose $+\mathrm{c}-\mathrm{Abl}$ siRNA for $24 \mathrm{~h} . * \mathrm{P}<0.05$ compared with cells exposed to normal glucose. ${ }^{\#} \mathrm{P}<0.05$ compared with cells exposed to high glucose. C and D: Representative Hoechst 33258 staining 
of apoptotic podocytes (original magnification $\times 400$, scale, $20 \mu \mathrm{m}$ ) and flow cytometry analysis of apoptosis in cultured podocytes with different medium and quantitation of these results $(n=3, n$ represents the number of repeat times). (a): $5 \mathrm{mM}$ glucose for $24 \mathrm{~h}$. (b): $5 \mathrm{mM}$ glucose $+25 \mathrm{mM}$ mannitol for $24 \mathrm{~h}$. (c): $30 \mathrm{mM}$ glucose for $24 \mathrm{~h}$. (d): $30 \mathrm{mM}$ glucose + c-Abl siRNA for 24 h. $* \mathrm{P}<0.05$ compared with cells exposed to normal glucose. ${ }^{\#} \mathrm{P}<0.05$ compared with cells exposed to high glucose.

\section{Figure 5:}

Effect of high glucose on the interaction between c-Abl and $\mathrm{p} 53$ in vitro. Co-immunoprecipitation result of the interaction between c-Abl and p53 in cultured podocytes with different medium and quantitation of these results ( $n=3, n$ represents the number of repeat times ). (a): $5 \mathrm{mM}$ glucose for 24 h. (b): $5 \mathrm{mM}$ glucose $+25 \mathrm{mM}$ mannitol for 24 h. (c): $30 \mathrm{mM}$ glucose for 24 h. (d): $30 \mathrm{mM}$ glucose + c-Abl siRNA for $24 \mathrm{~h}$. $* \mathrm{P}<0.05$ compared with cells exposed to normal glucose. ${ }^{\#} \mathrm{P}<0.05$ compared with cells exposed to high glucose. 

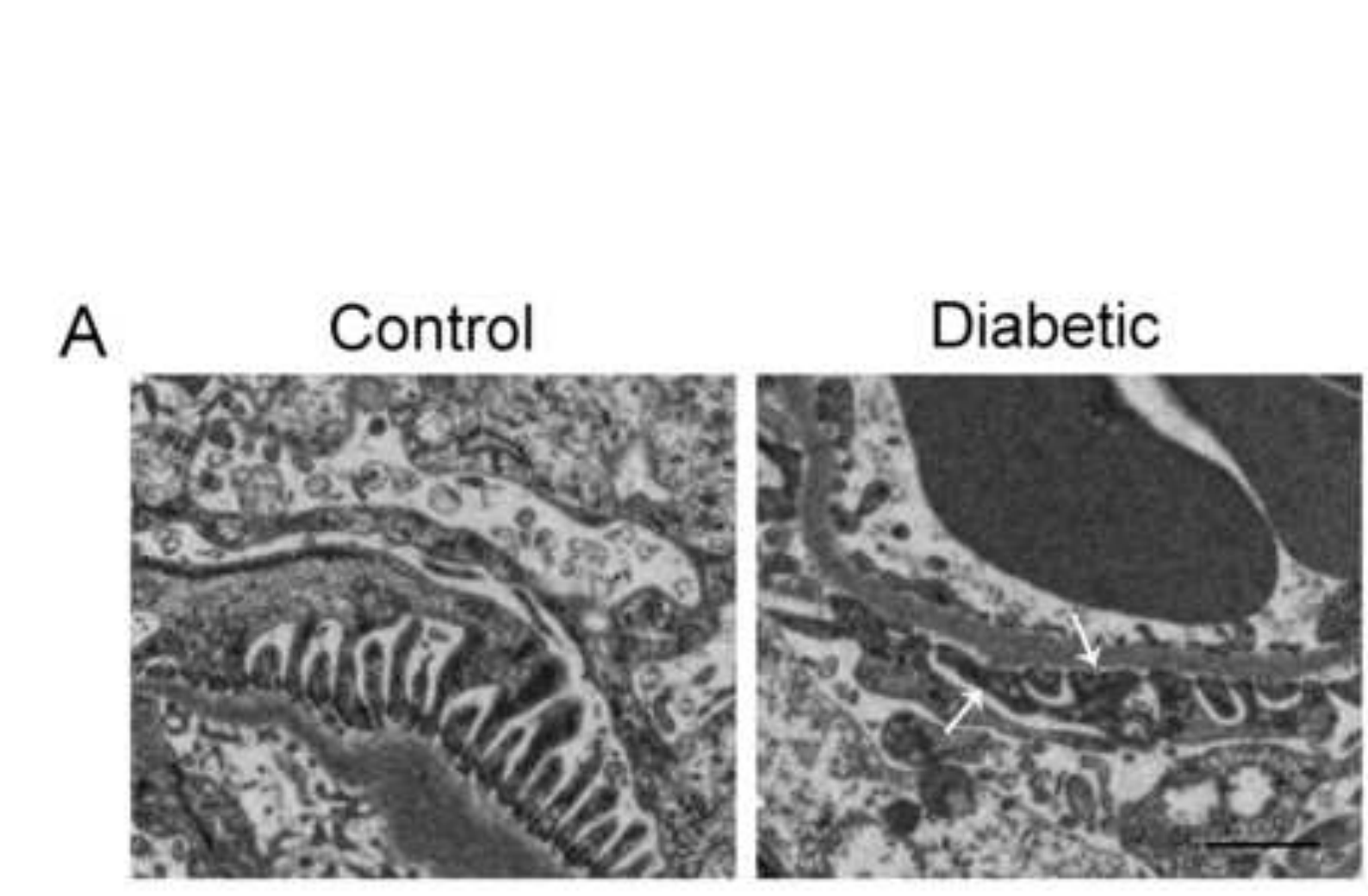
B

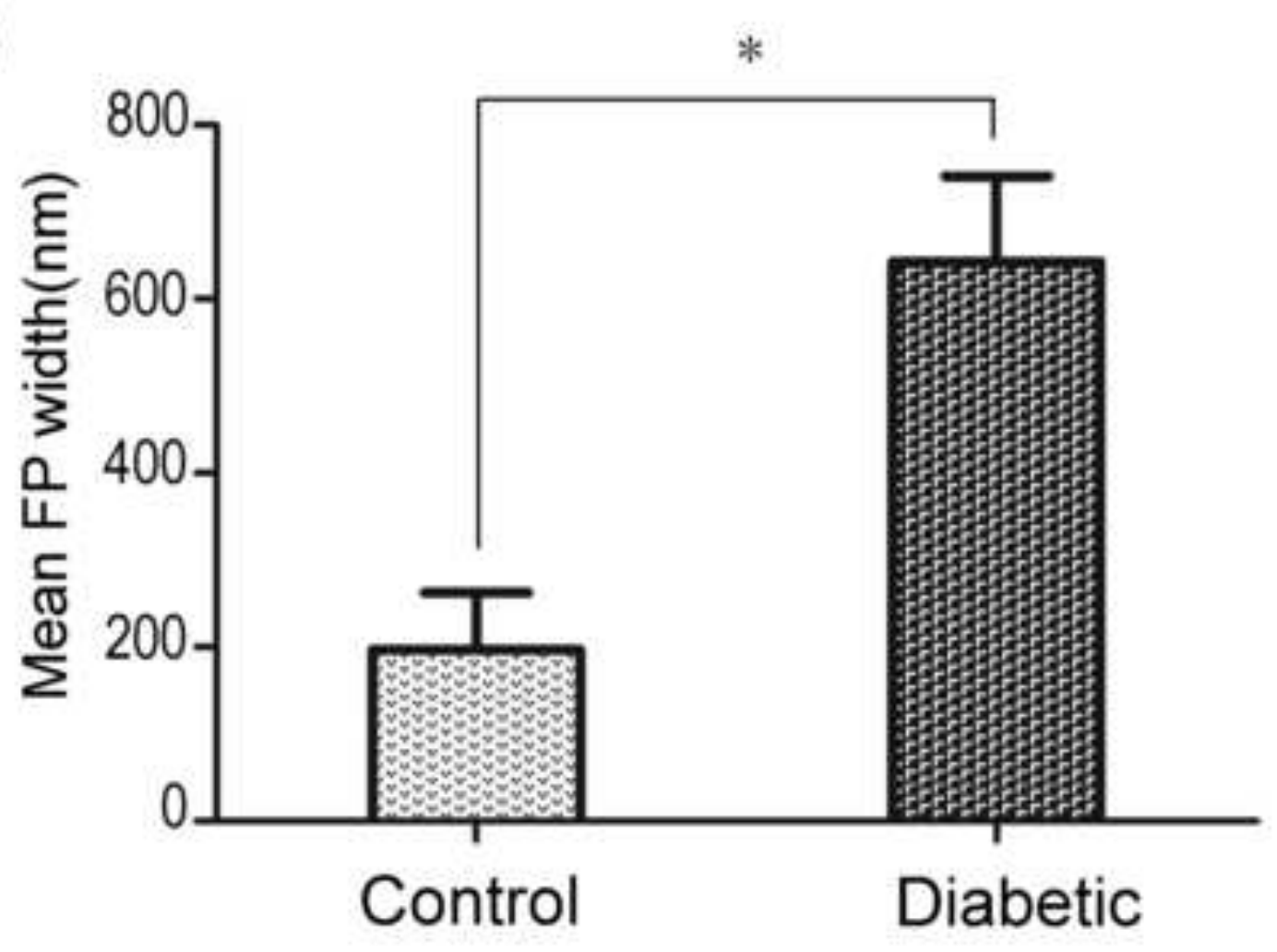

Figure 1

\section{Diabetic}

\section{(}

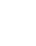

(

.

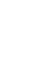


A

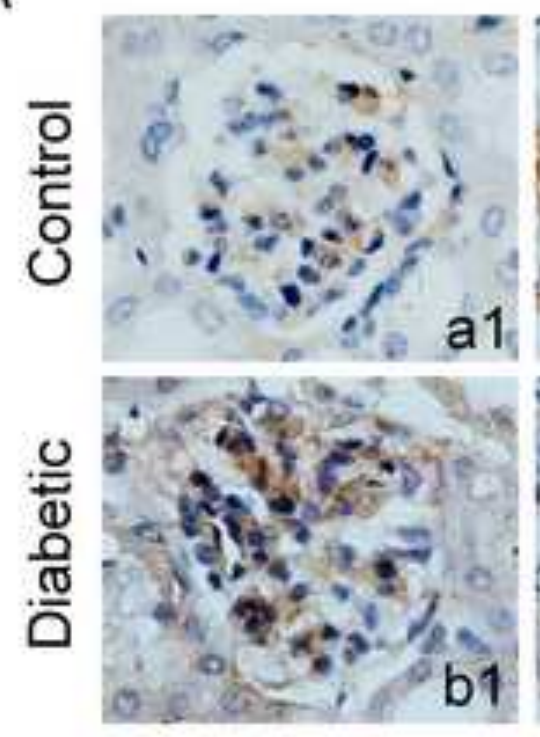

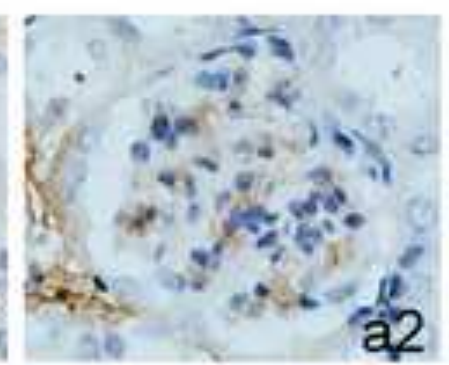

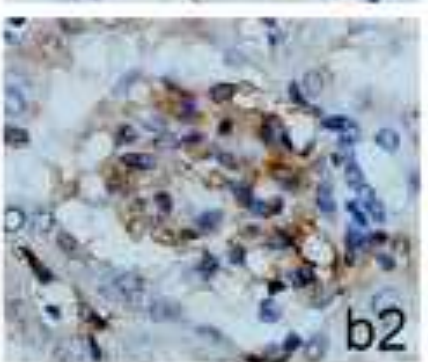

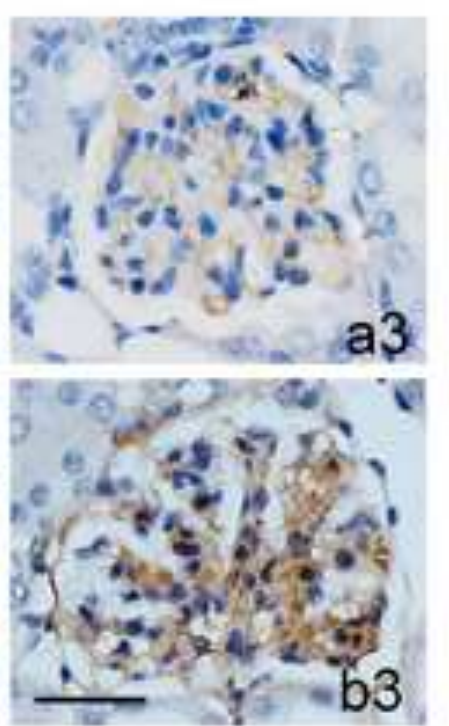

B

C

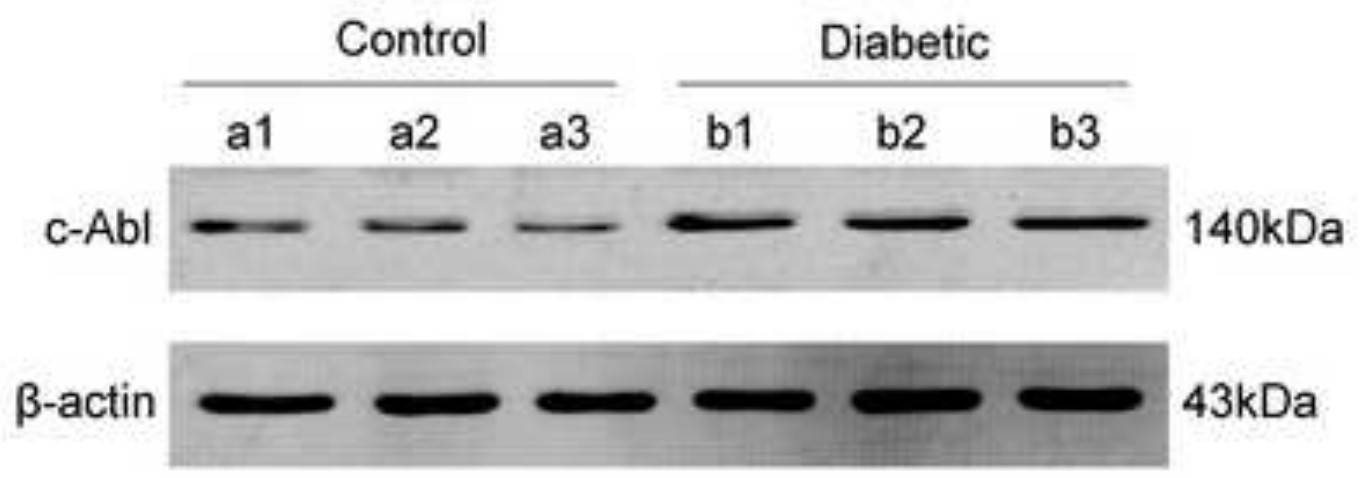

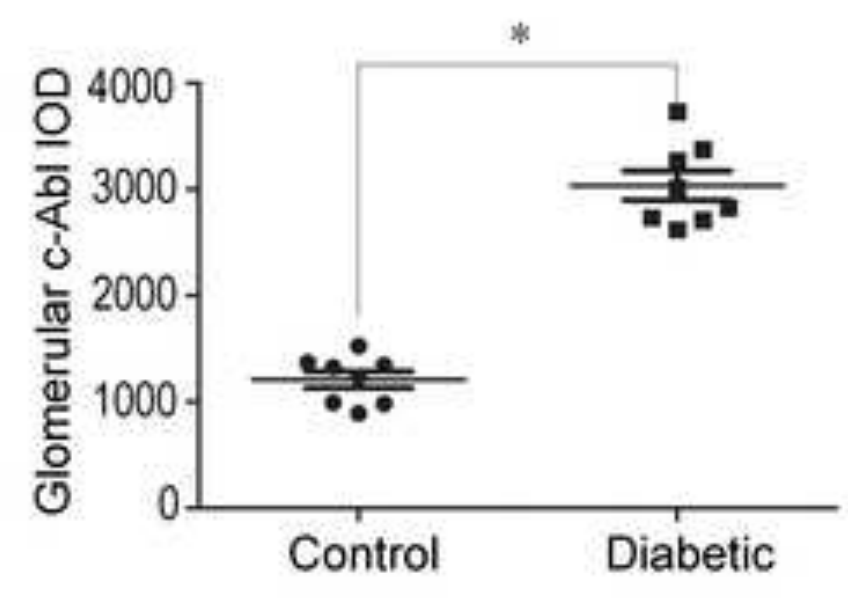

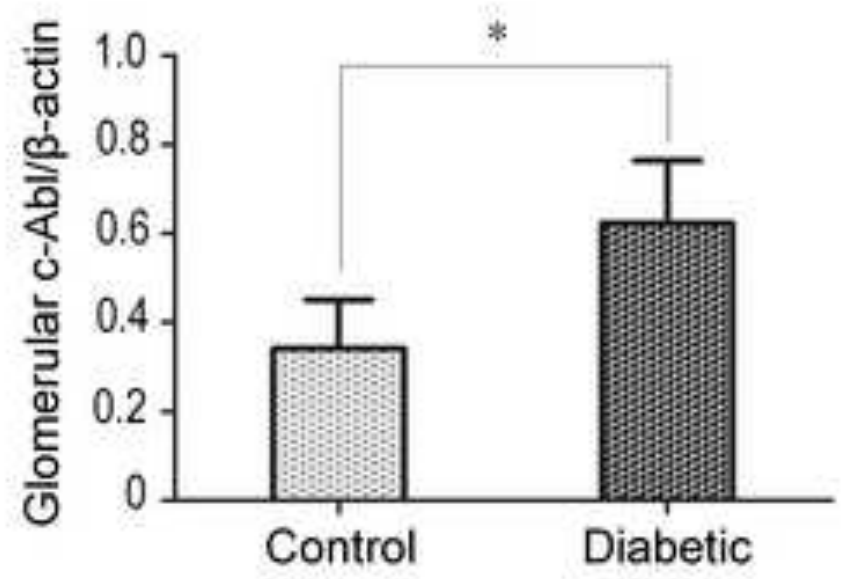


A

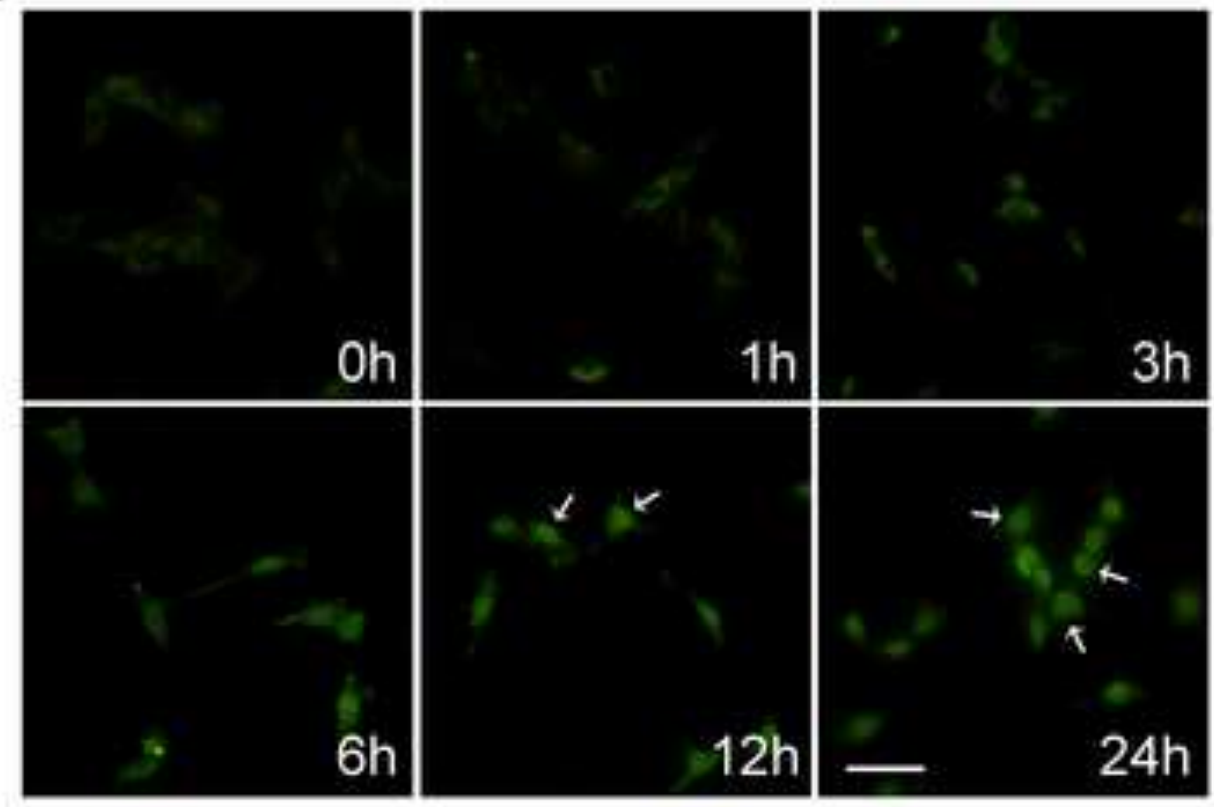

C

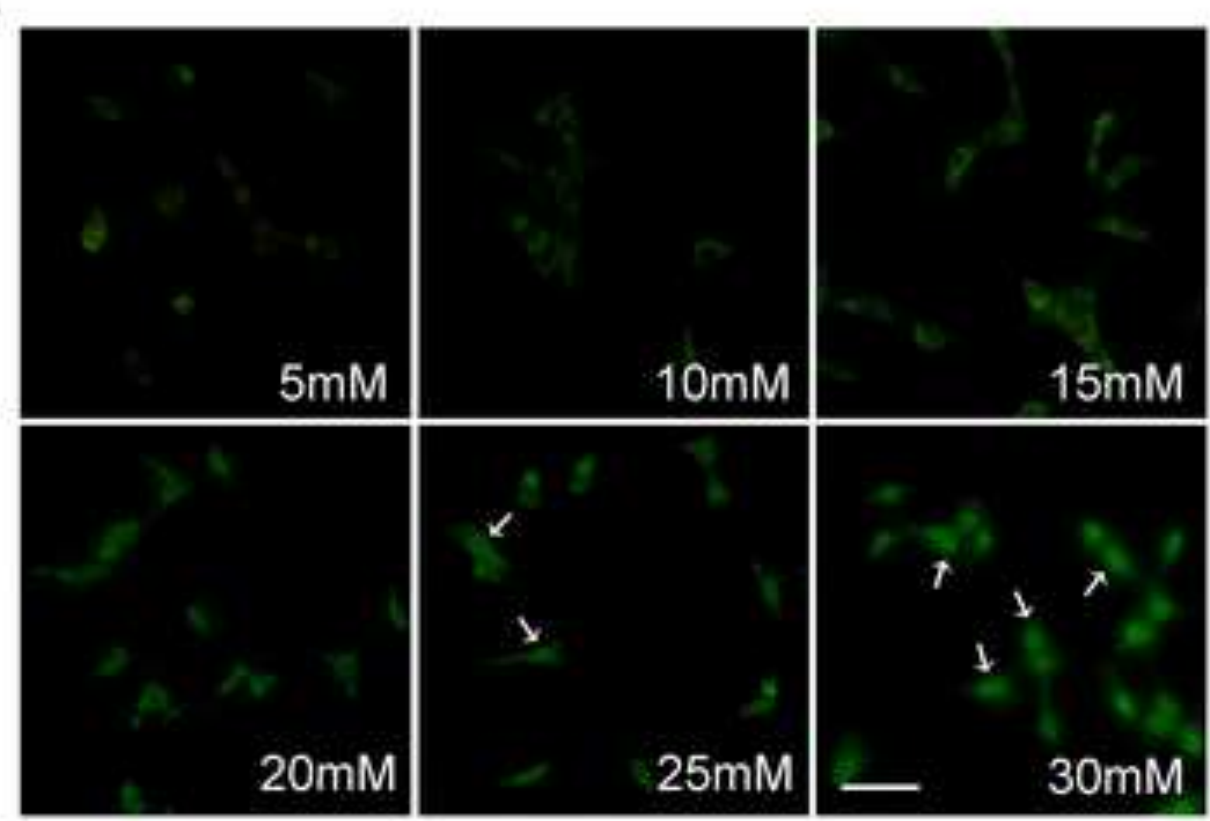

B
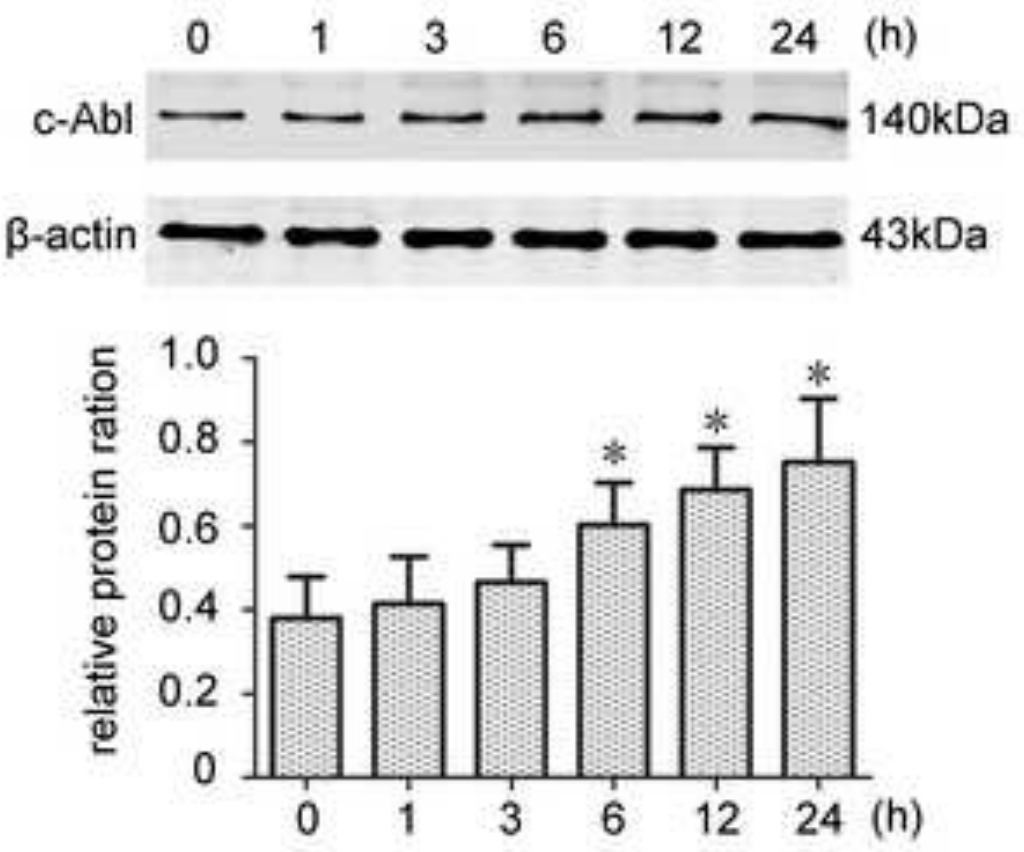

D
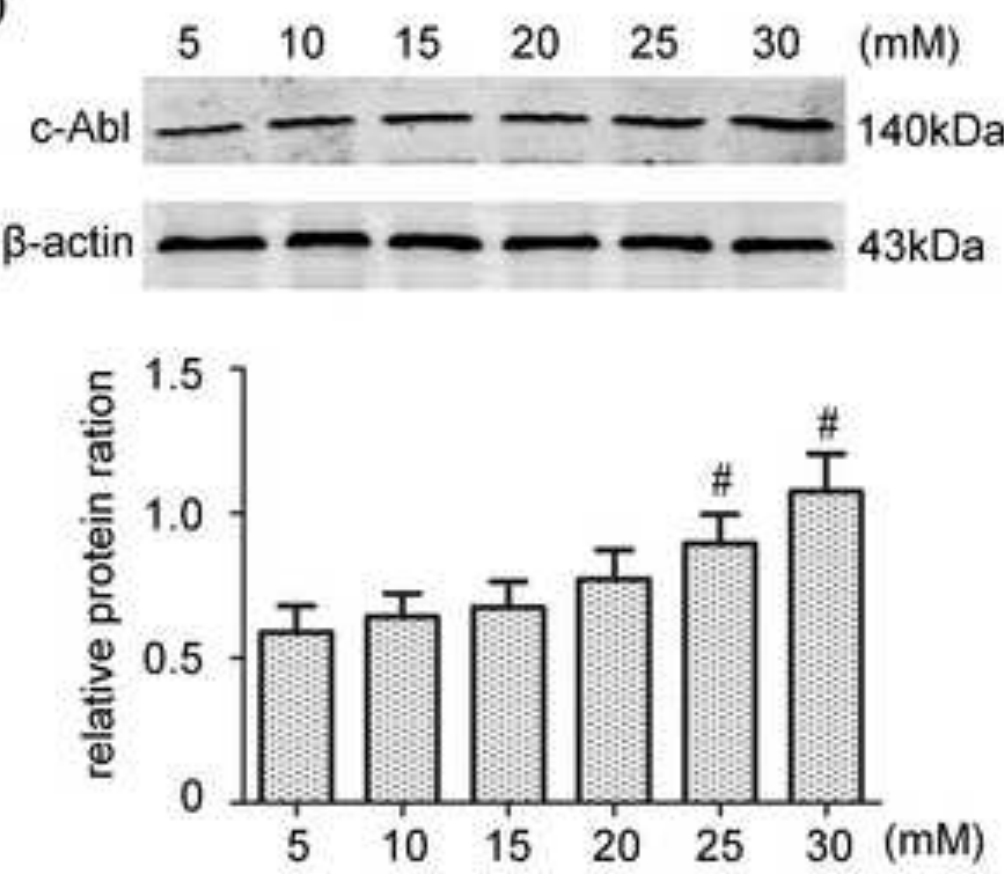
A
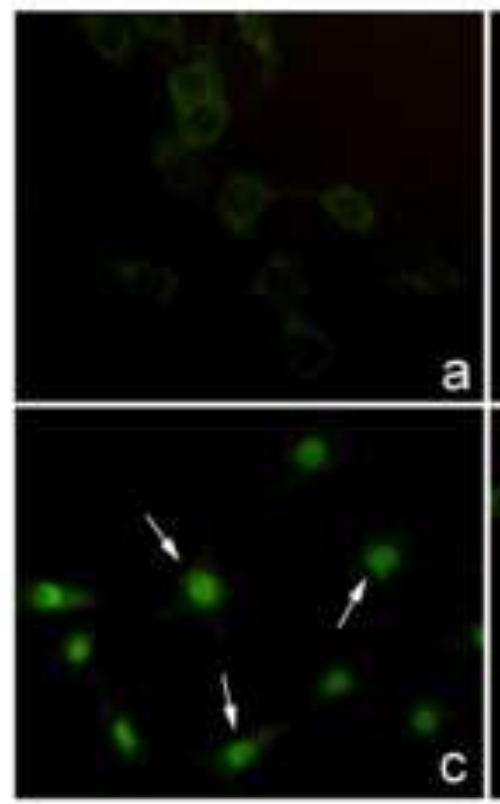

C

C

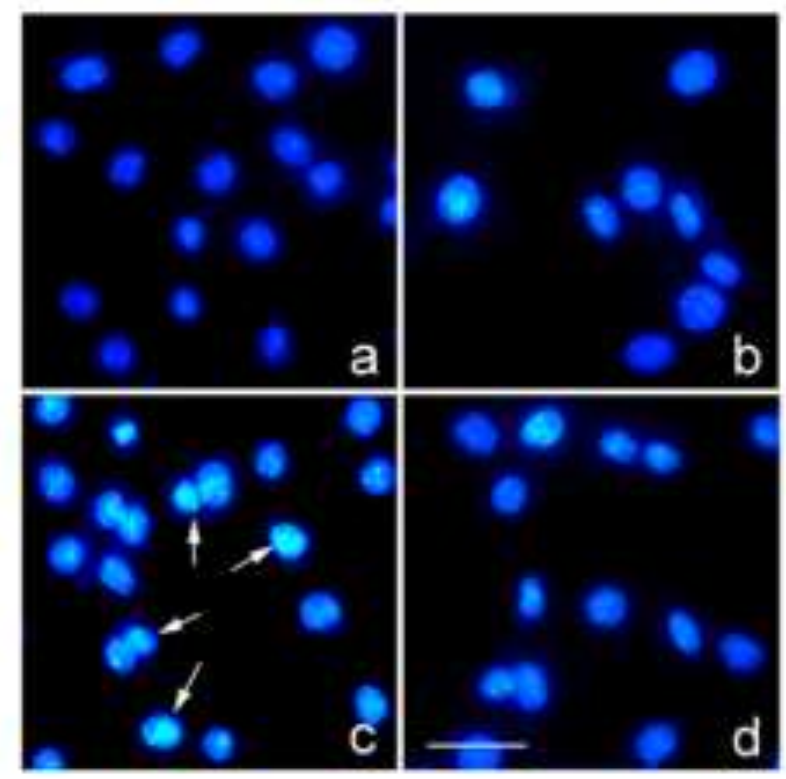

B
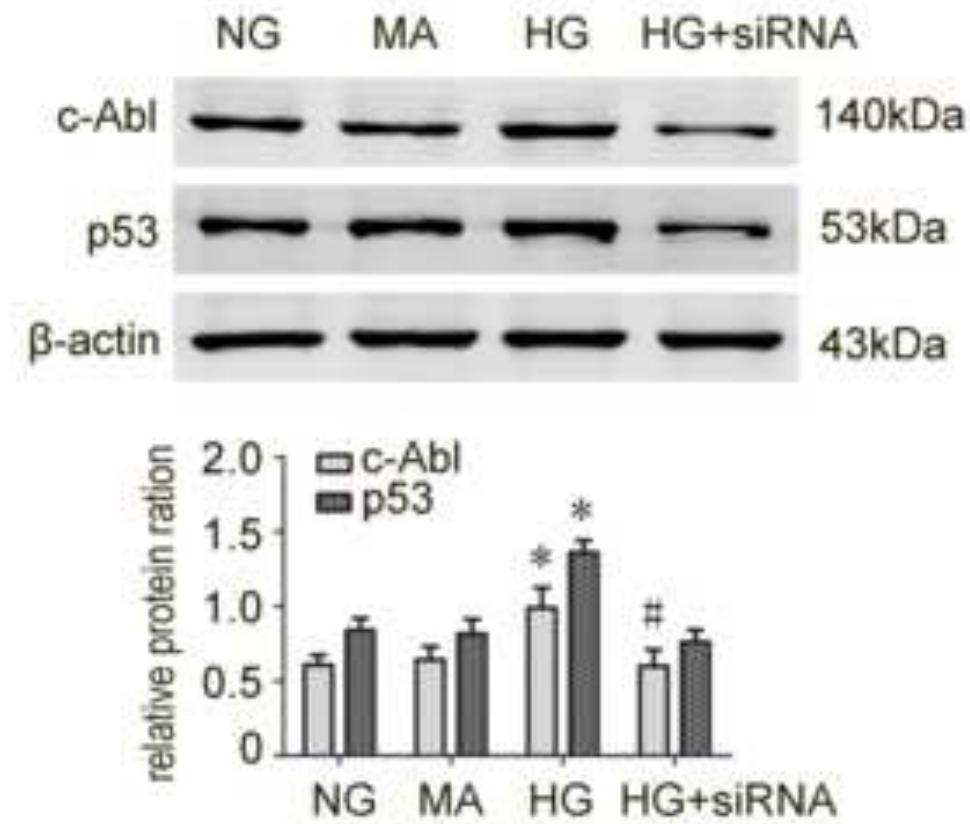

D
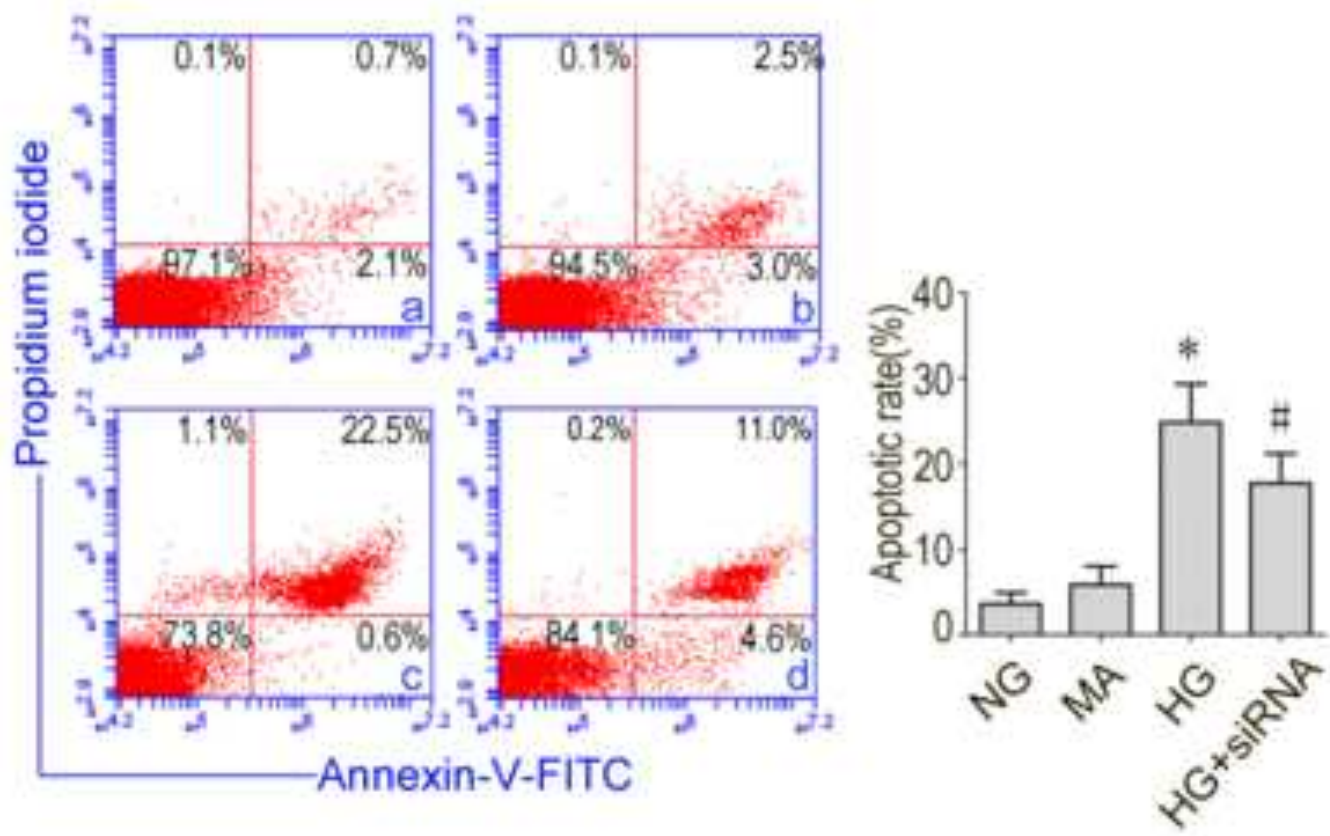


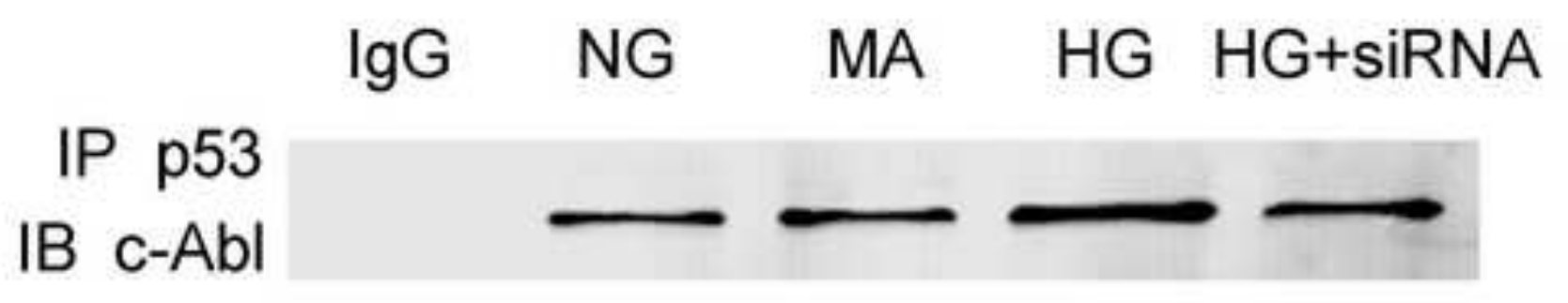

IP p53
IB p53

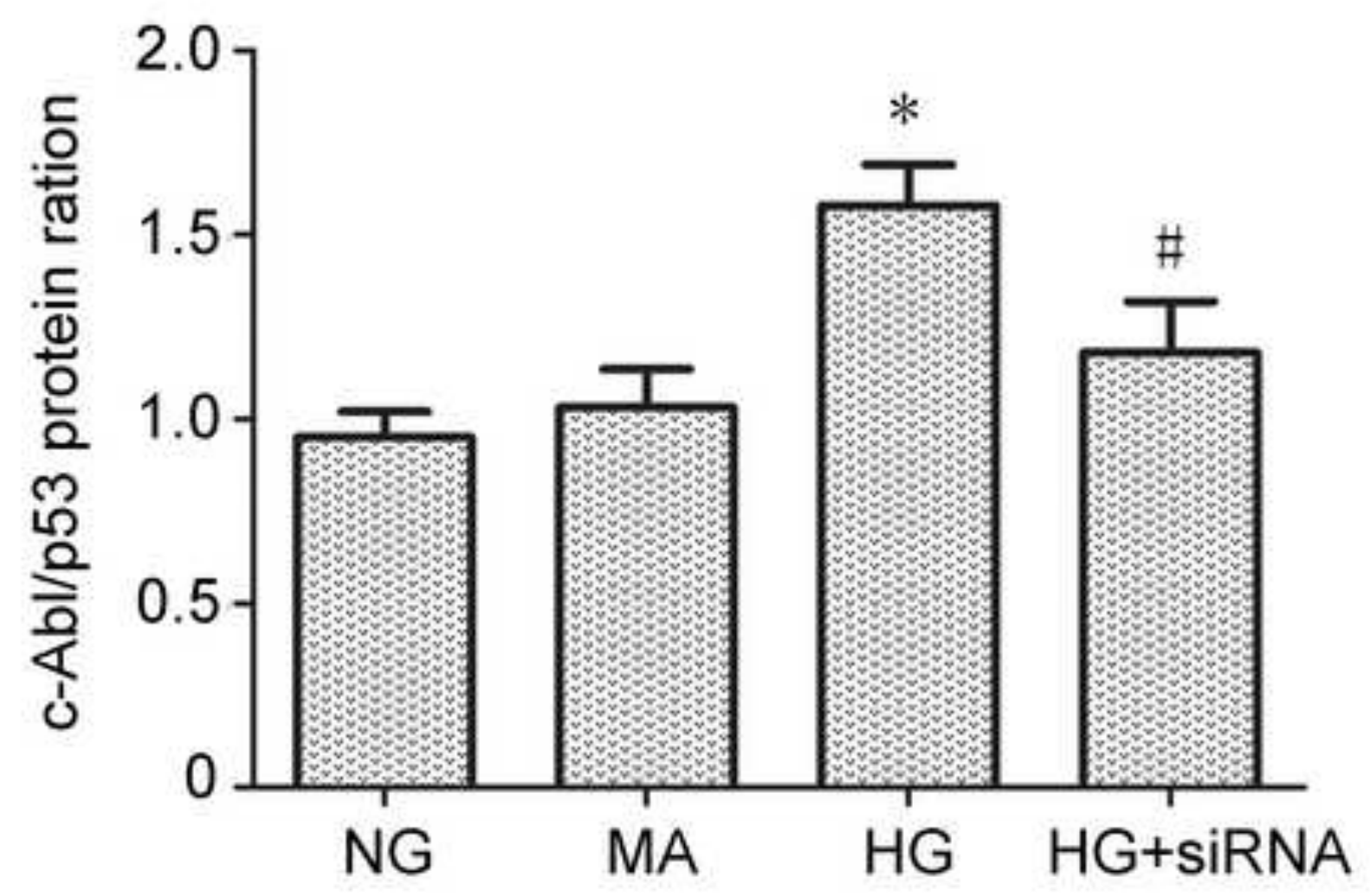


Table 1

Biochemical values of each group at the end of 12 week $(\bar{\chi} \pm s)$

\begin{tabular}{lccll}
\hline Group & $\mathrm{N}$ & $\mathrm{BG}(\mathrm{mmol} / \mathrm{L})$ & $\mathrm{KW} / \mathrm{BW}(\mathrm{mg} / \mathrm{g})$ & $\mathrm{UAE}(\mathrm{ug} / 24 \mathrm{~h})$ \\
\hline Control & 8 & $5.63 \pm 0.67$ & $7.92 \pm 0.37$ & $68.42 \pm 12.33$ \\
Diabetic & 8 & $23.49 \pm 2.82 *$ & $12.08 \pm 0.54 *$ & $895.61 \pm 104.28^{*}$ \\
\hline
\end{tabular}

BG: blood glucose; KW: kidney weight; BW: body weight;

UAE: urinary albumin excretion.

${ }^{*} p<0.05$ compared with control group. 